\title{
The influence of interferon- $\gamma$ on cardiac and renal histopathological changes induced by carbamazepine
}

\author{
Bahmanpour $\mathrm{S}^{1,2}$, Karimi $\mathrm{F}^{2,3}$, Soleimani $\mathrm{A}^{2}$, Kamali $\mathrm{M}^{4}$, Namavar $\mathrm{MR}^{2,3,5}$ \\ Laboratory for Stem Cell Research, Department of Anatomical Sciences, School of Medicine, \\ Shiraz University of Medical Sciences, Shiraz, Iran. bahmans@sums.ac.ir
}

\begin{abstract}
BACKGROUND: Carbamazepine (CBZ) is used for the treatment of epileptic seizures. This study was designed to evaluate the effect of Interferon-gamma on the fetal heart and kidney histopathological changes of CBZ-treated pregnant mice.

METHODS: Twenty pregnant mice were divided into four groups. The control group received distilled water. The second group received $240 \mathrm{mg} / \mathrm{kg}$ of CBZ by gastric gavage. The third group received intraperitoneal injection (IP) of IFN-ץ. The fourth group received IP injection of IFN- $\gamma$ with $240 \mathrm{mg} / \mathrm{kg}$ CBZ by gavage. The fetuses were delivered by hysterectomy on the 18th day of gestation.

RESULTS: The mean weight, crown-rump length, the total volume of the heart and kidney of the fetuses in the CBZ-treated group were significantly reduced when compared with the control, INF- $\gamma$ and CBZ + INF- $Y$ groups $(p<0.05)$. INF-y prevented histopathological changes when used with CBZ $(p<0.05)$.

CONCLUSION: CBZ induced structural changes in the fetal tissues of the pregnant mice. However, IFN- $\gamma$ could reduce these changes (Tab. 1, Fig. 4, Ref. 26).

KEY WORDS: carbamazepine, interferon- $\gamma$, heart, kidney, mice.
\end{abstract}

\section{Introduction}

Epilepsy is one of the common nervous system disorders affecting about $0.3-0.7 \%$ of pregnancies (1). Children born to mothers with epilepsy are at increased risk for low birth weight, prematurity, neonatal death, congenital malformations (2). On the other hand, women with epilepsy must use antiepileptic drugs (AEDs) during pregnancy (3). AEDs (e.g. valproic acid, carbamazepine and diazepam) may affect the fetal development during pregnancy (4). The most frequent disorders related to AEDs are heart malformations, urologic defects, neural tube defects (NTDs), orofacial clefts and skeletal abnormalities (2). Hence, finding the ways of inhibiting AED-related abnormalities is a vital factor in the treatment of epileptic mothers and their offspring. Carbamaze-

${ }^{1}$ Laboratory for Stem Cell Research, Department of Anatomical Sciences, School of Medicine, Shiraz University of Medical Sciences, Shiraz, Iran, ${ }^{2}$ Department of Anatomical Science, School of Medicine, Shiraz University of Medical Sciences, Shiraz, Iran, ${ }^{3}$ Histomorphometry and Stereology Research Center, Shiraz University of Medical Sciences, Shiraz, Iran, ${ }^{4}$ Department of Biology, Jahrom Branch, Islamic Azad University, Jahrom, Iran and Young Researchers and Elite Club, and ${ }^{5} \mathrm{Clinical}$ Neurology Research Center, Shiraz University of Medical Sciences, Shiraz, Iran

Address for correspondence: $\mathrm{S}$. Bahmanpour, $\mathrm{PhD}$, Laboratory for Stem Cell Research, Department of Anatomical Sciences, School of Medicine, Zand Blvd, Shiraz, Iran

Phone/Fax: +98.7132304372

Acknowledgement: This study was supported by the grant No. 10348, from Shiraz University of Medical Sciences in Shiraz, Iran. The work was performed at Histomorphometry and Stereology Research Centre, Shiraz University of Medical Sciences, Shiraz, Iran. pine (CBZ) is one of the oldest AEDs applied worldwide. There are many researches to show that CBZ is a teratogen (5). Children of mothers with epilepsy which used CBZ during pregnancy showed an increased rate of congenital abnormalities such as cardiovascular and urinary tract anomalies, NTDs, cognitive failure and cleft palate. It may cause impairment in the fetus because it crosses the placenta (5). The concentrations of CBZ in the blood were much lower than those in the brain, lung, liver and kidney. It means that the highest blood CBZ concentration is incorporated into these organs (6). In the same vein, there have been various studies indicating the effectiveness of maternal immune stimulation (MIS) in preventing the birth defects (7). Previous studies showed that MIS seems to have an extensive range of efficacy for decreasing teratogen-induced birth deficiencies from a range of agents including hyperthermia, chemical mediators and x-rays (8). MIS blocked or reduced NTDs $(9,10)$, craniofacial defects (11), limb defects and tail abnormalities (12). Very limited evidence is accessible about mechanisms mediating these protective effects. It is known that immune cells, comprising NK cells and macrophages, and cytokine products of these cells play serious roles during pregnancy (13). Immune cell or cytokine pathway disorders by teratogens could harmfully affect the pregnancy outcome. In other investigations, MIS with interferon-gamma (IFN- $\gamma$ ) reduced malformations of the fetal limb and enhanced the placental integrity $(11,14)$. IFN- $\gamma$ is a soluble cytokine that has special effects on the vascularized allografts, containing induction of MHC and protection contrary to necrosis. Also, biomedical alterations following IFN- $\gamma$ have been investigated in several studies (14). Recently studies revealed that MIS with IFN- $\gamma$ decreased the prevalence 
613-618

of diabetes induced NTDs, ocular and craniofacial defects $(7,9$, 10). So, we hypothesized that MIS with the same cytokine would decrease the incidence of teratogenic effects of CBZ. To date, there are no efforts to study the quantitative anatomical landscapes of the mouse embryo tissues after exposure to $\mathrm{CBZ}$ and the possible protective role of INF- $\gamma$. The first goal of this study was to assess the histological teratogenic effects of $\mathrm{CBZ}$ during pregnancy. The second aim was to evaluate the possible protective effect of IFN- $\gamma$ on the histopathological changes in the fetal heart and kidney following exposure to CBZ.

\section{Methods}

\section{Animals}

Twenty BALB/c pregnant mice, aged 8-12 weeks old and weighing 25-35 g were purchased from Comparative and Experimental Medicine Center of Shiraz University of Medical Sciences (SUMS). The animal trial was approved by the Ethics Committee of the University (approval No.10348) and all manipulations were done under the regular commands of the Animal Ethics Committee of SUMS. The animals were divided into four groups. Each group included 5 mice kept under standard conditions with free access to food and water. The control and carbamazepine (CBZ) groups received distilled water and $240 \mathrm{mg} / \mathrm{kg}$ of CBZ by gastric gavage on the gestational days (GD) 7, 8, 9, 13, 14, respectively. The third (INF- $\gamma$ ) group received intraperitoneal (IP) injection of IFN- $\gamma(1000 \mathrm{IU})$ on GD 7 (14). The fourth (CBZ + INF- $\gamma$ ) group received IP injection of IFN- $\gamma$ on GD 7 with $240 \mathrm{mg} / \mathrm{kg} \mathrm{CBZ}$ by gavage on GD 7, 8, 9, 13, 14 (15).

\section{Tissue preparation}

The fetuses were delivered by hysterectomy on the 18th day of gestation. Five fetuses were selected randomly from each group. The body weight and crown-rump length (CRL) of each fetus were recorded. The hearts and kidneys were removed, processed, sectioned $(25 \mu \mathrm{m})$, and stained by hematoxylin and eosin (H\&E).

Then, the systematic random sampled sections (8-10 sections per animal) were examined under light microscope to be evaluated for stereological and histopathological parameters.

\section{Estimation of the volume}

For the volume estimation, we used point counting method based on Cavalier's principle. Briefly, images of the sections were projected on the monitor and superimposed by stereology software (Stereo Lite, SUMS, Shiraz, Iran). We estimated the volume of the heart and kidney $(\mathrm{V})$ by applying the following formula:

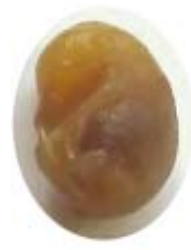

CON

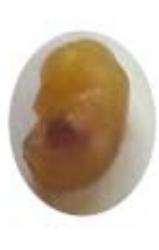

CBZ

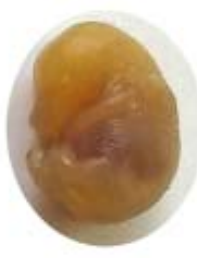

IFN

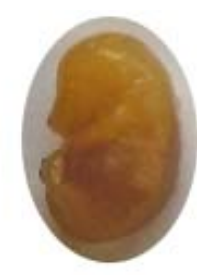

$\mathrm{CBZ}+\mathrm{IFN}$
Fig. 1. Mouse fetuses were collected on day 18 of pregnancy. Marked difference was found in the crown-rump length and body weight of the fetuses in the $\mathrm{CBZ}$ group in comparison to the control group. The results did not show significant changes in these parameters in the other experimental groups compared to the control animals. CON: Control, CBZ: Carbamazepine, IFN- $\gamma$ : Interferon- gamma. Scale bar $=0.1 \mathrm{~mm}$.

$\mathrm{V}=\mathrm{d} \times \mathrm{t} \times a(p) \times \Sigma \mathrm{P}$, where " $\mathrm{d}$ " is the average distance from one section to the next. " $\mathrm{t}$ " is the mean section thickness, " $a / p$ " is equal to the area associated with one point in the grid, and " $\Sigma \mathrm{P}$ " is the number of points hitting the area of the heart or kidney (16).

\section{Histopathological evaluation}

The histopathological examination was performed using the cardiac and renal tissue from each group. Cardiac tissue injury scores were as follows: $(0=$ Absent; $0.5=$ Trace $1=$ Mild; $2=$ Moderate; 3 = Severe) (17); also, renal tissue injury scores were $(0=$ No reaction; $1-4=$ Minimal, $5-8=$ Mild; $9-12=$ Moderate; $13-18=$ Severe) $(18)$.

\section{Statistical analysis}

The data were expressed as mean \pm SEM. Statistical analysis was performed through one-way ANOVA followed by post-hoc Tukey's test. $\mathrm{p} \leq 0.05$ was considered to be statistically significant. The statistical analyses were done using the SPSS statistical package (Version 22, Release 22.0.0, IBM, 2015, USA).

\section{Results}

\section{Estimation of parameters}

The results showed that the body weight as well as heart and kidney weights decreased in the CBZ-treated group in comparison with the control group (Tab. 1). It also showed a significant decrease in crown-rump length of the CBZ group when compared with the control group. However, after stimulation of the maternal immune system of CBZ-treated with INF- $\gamma$, this substance significantly prevented these parameters changes $(\mathrm{p}<0.05)$ (Tab. 1).

Tab. 1. Mean \pm SD of body weight, crown-rump length, and heart and kidney weight of mouse embryo in different groups.

\begin{tabular}{lccc}
\hline \multirow{2}{*}{ Parameter } & \multicolumn{2}{c}{ Groups } \\
\cline { 2 - 4 } & CON & CBZ & IFN- $\gamma$ \\
\hline Body weight (gr) & $1.21 \pm 0.13$ & $0.97 \pm 0.16^{*}$ & $1.14 \pm 0.09$ \\
Crown-rump length (mm) & $23.50 \pm 1.41$ & $16.70 \pm 2.99 *$ & $20.88 \pm 1.93$ \\
Heart (gr) & $0.0038 \pm 0.0004$ & $0.0016 \pm 0.0002 *$ & $20.31 \pm 1.50$ \\
Kidney (gr) & $0.0018 \pm 0.0002$ & $0.0009 \pm 0.0001 *$ & $0.0038 \pm 0.0005$ \\
\hline
\end{tabular}

CON: control; CBZ: carbamazepine; INF: Interferon- $\gamma,{ }^{*} \mathrm{p}<0.01$ (CBZ vs control, IFN and CBZ+ IFN) 
A

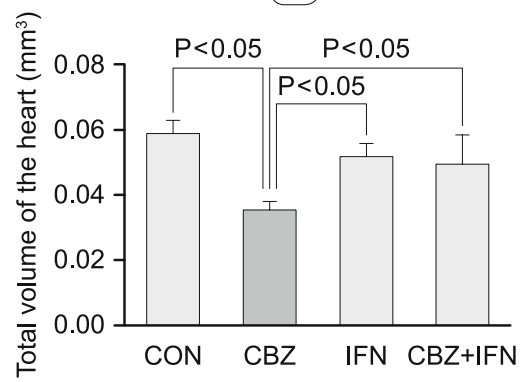

(D)

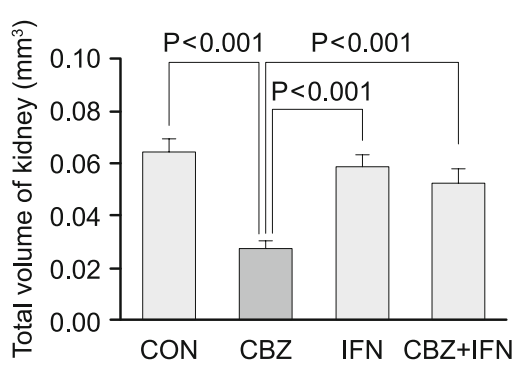

B

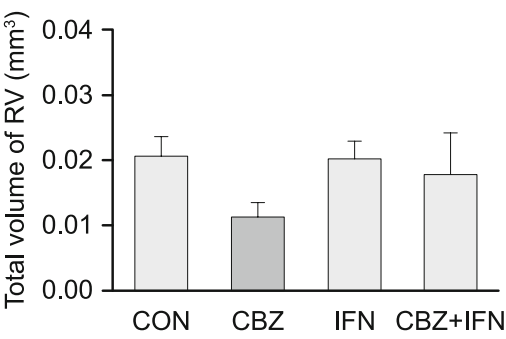

E

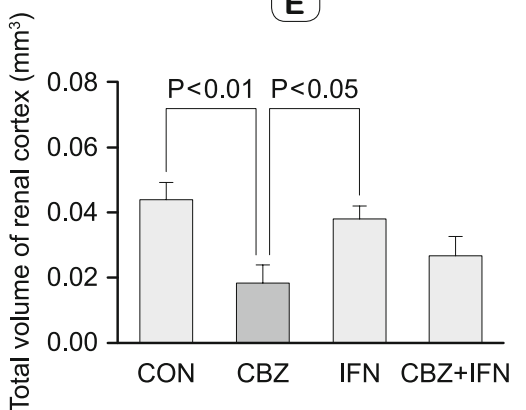

(C)

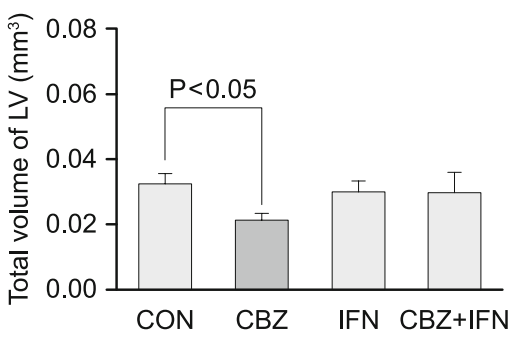

Fig. 2. Bar graphs showing the total volume of the heart (A), right ventricle (B), left ventricle (C), total volume of the kidney (D), renal cortex (E) and renal medulla (F) in CON, CBZ, IFN- $\gamma$ and $\mathrm{CBZ}+\mathrm{IFN}-\gamma$ groups. Data represent Mean $\pm \mathrm{SEM}(\mathrm{n}=5$ ). One-way analysis of variance (ANOVA) and post hoc Tukey's test were used as statistical test. P-values are shown. CON: Control, CBZ: Carbamazepine, IFN- $\gamma$ : Interferon gamma, RV: Right ventricle, LV: Left ventricle.

Figure 1 represents a significant decrease in the body size of the fetuses in the CBZ group as compared with the control group. Meanwhile, INF- $\gamma$ was found to potentially prevent these changes.

\section{Volume of the heart and ventricles}

The data are presented in Figure 2. The total volume of the heart and left ventricle were reduced in the CBZ-treated group as compared to the control and INF- $\gamma$ groups $(p<0.05)$. The decreased total volume of the heart in $\mathrm{CBZ}$ group was however restored by INF- $\gamma$ treatment $(p<0.05)$.

\section{Volume of the kidney, cortex and medulla}

The results related to the kidney are presented in Figure 2. As the figure shows, the total volume of the kidney, renal cortex and medulla was reduced in the CBZ-treated group in comparison to the control and INF- $\gamma$ groups $(p<0.01)$. Yet, the treatment of CBZ treated group with INF- $\gamma$ protected the loss of the total volume of the kidney and medulla $(\mathrm{p}<0.05)$.

\section{Heart histopathological evaluation}

Examination of the fetal cardiac sections in the control and INF- $\gamma$ groups showed normal histological structure of the myocardium. The most alterations were observed in the CBZ group. This group showed loss of normal tissue appearance with degeneration of the cardiomyocyte and hyperemic blood vessels. However, treatment of $\mathrm{CBZ}$ group with Interferon- $\gamma$ resulted in reduction of the damage (Fig. 3A). The score of cardiac tissue damage (Fig. $3 \mathrm{~B} \& \mathrm{C}$ ) was significant in the $\mathrm{CBZ}$ group when compared with the other groups $(\mathrm{p}<0.01)$.

\section{Kidney histopathological evaluation}

Examination of the fetal kidney sections in the control and INF- $\gamma$ groups showed normal renal structure. However, the CBZ group showed degeneration of the proximal and distal tubules with enlarged urinary space and inflammatory infiltrate cells in the CBZ group. On the other hand, these alternations were less significant in the CBZ + INF- $\gamma$ group (Fig. 4A). The score of the renal tissue damage (Fig. 4B\&C) was significantly higher in the CBZ group when compared with the other groups $(p<0.01)$.

\section{Discussion}

The present research attempted to study the effect of CBZ and IFN- $\gamma$ use during pregnancy on quantitative and histopathological changes of the fetal vital organs. The first part of the current study showed that CBZ used in pregnant mice reduced the CRL and body weight as well as fetal heart and kidney weights. These results are consistent with pervious researches that showed CBZ can lead to intrauterine growth retardation which is manifested by low body weight and length reduction (19). Furthermore, Artama 
A
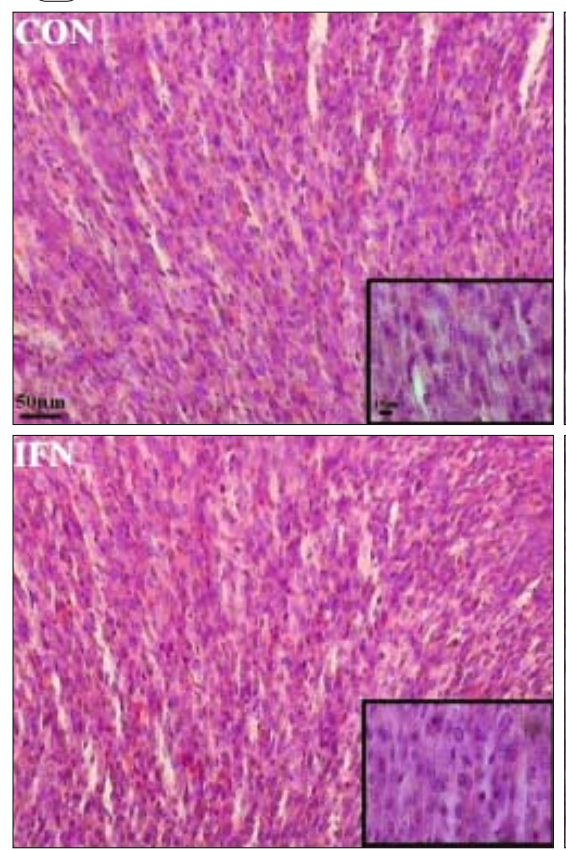
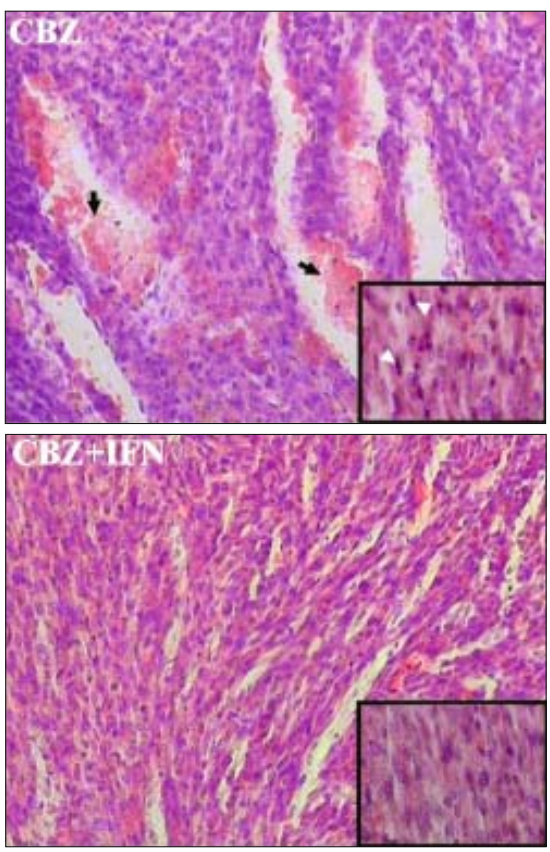

(B)

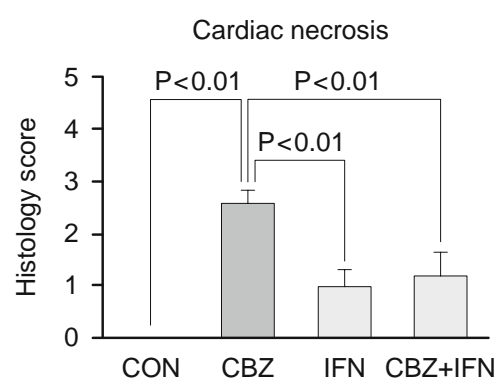

(C)

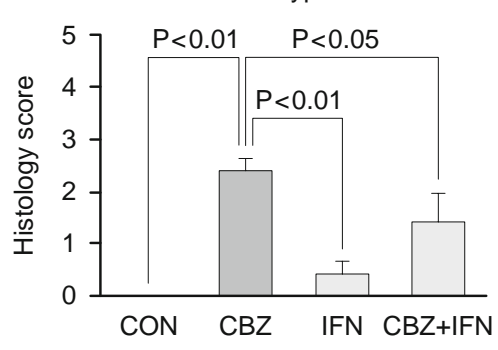

Fig. 3. Photomicrographs of the fetal cardiac tissue from CON, CBZ, IFN- $\gamma$ and CBZ + IFN- $\gamma$ groups (A). The heart tissue in the control group showed normal morphology of the cardiomyocytes. Panel CBZ shows the histopathological finding with the hyperemic blood vessels (arrows) and cardiomyocyte necrosis with the pyknotic nucleus (arrowhead) in this group in comparison to the control group. IFN- $\gamma$ group was similar to the control group; however, CBZ+IFN- $\gamma$ showed a decrease in the $\mathrm{CBZ}$ effects on cardiac changes. (B\&C) Bar graphs show the fetal cardiac tissue injury scores in the groups CON, CBZ, IFN- $\gamma$ and CBZ+ IFN- $\gamma$ groups, according to the histopathological evaluation. CON: Control, CBZ: Carbamazepine, IFN- $\gamma$ : Interferon gamma.

(A)
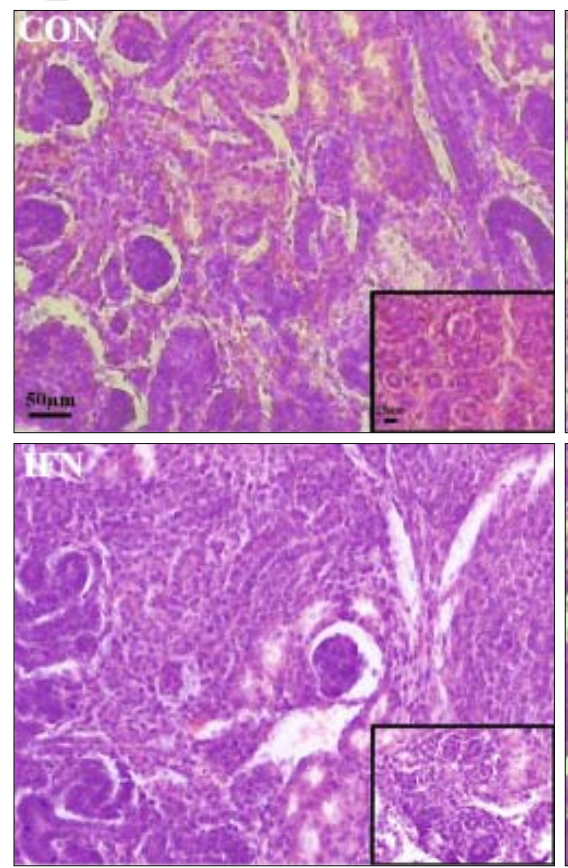
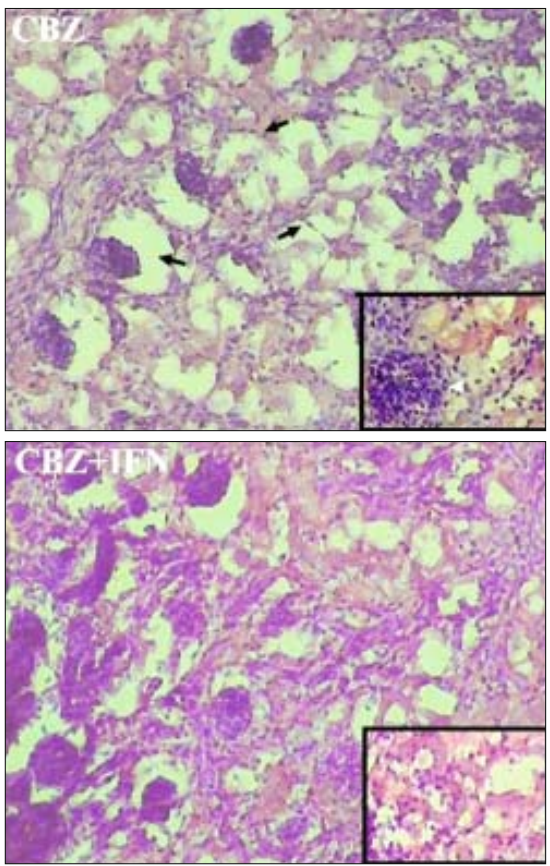

(B)

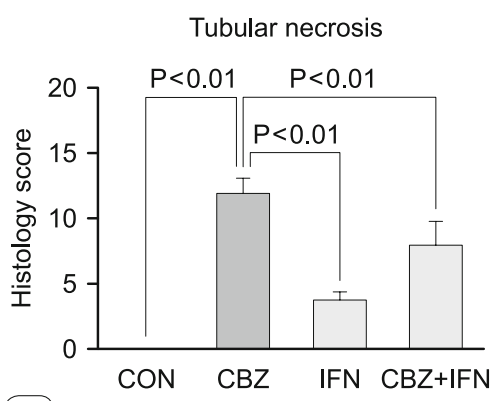

(C)

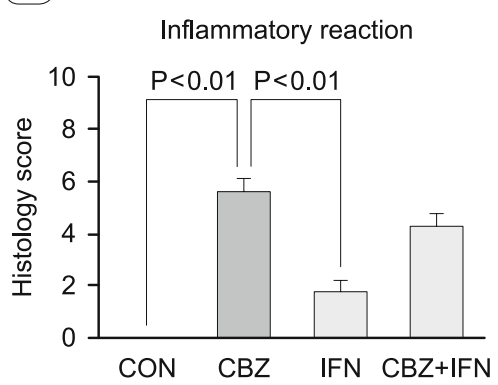

Fig. 4. Photomicrographs of the fetal renal tissue in the groups CON, CBZ, IFN- $\gamma$ and CBZ+ IFN- $\gamma$ groups (A). No histopathological findings were observed in the glomerulus and convoluted tubules in the control group. Arrows show degeneration of the convoluted tubules and renal corpuscles with widening of the Bowman's space; arrowhead shows inflammatory infiltrate cells in the CBZ group. In groups IFN- $\gamma$ and CBZ+IFN- $\gamma$, these effects were diminished. (B\&C) Bar graphs show the fetal renal tissue injury scores in the groups CON, CBZ, IFN- $\gamma$ and CBZ+ IFN- $\gamma$ groups, according to the histopathological evaluation. CON: Control, CBZ: Carbamazepine, IFN- $\gamma$ : Interferon gamma. 
et al (2005) reported that prenatal contact with CBZ may prompt growth retardation, leading to disturbance of the growth hormoneinsulin interaction (20). Moreover, previous studies showed a significant decline in the body and organ weight, limb length and congenital abnormalities in the offspring of mice cured with CBZ (19).

The findings of the second part of the present research indicated a reduction in the volume of the fetal heart and kidney following CBZ. This is consistent with our histopathological findings. The earlier studies indicated histopathological alterations of the tissues such as the liver, kidney and heart due to CBZ (21). Also, our findings showed hyperemic blood vessels and degeneration of cardiomyocyte of the fetal heart in the CBZ group. These results are in line with Elshama's study (2013) indicating that CBZ can lead to ventricular and atrial septal defect as well as degeneration of the myocardial muscle fibers (21). Moreover, our study illustrated degeneration of convoluted tubules with inflammatory infiltrate cells of the fetal kidney in the CBZ group. This data is in line with Okada's (2005) study results that showed CBZ can lead to degeneration of the renal tubules and atrophy of the glomeruli (22). Furthermore, Takayasu (2010) confirmed that concentrations of CBZ metabolites are much higher in the kidney, liver, lung, and brain than in the blood. This shows that $\mathrm{CBZ}$ is retained in the organs and can cause histopathological changes (6). A wide range of mechanisms have been proposed in regard to the adverse effect of CBZ. In general, CBZ is metabolized into oxidative intermediates. Clearance of CBZ metabolites depends on epoxide enzyme activity. Newborns with a reduced enzyme activity would probably be at an increased risk for anomalies if their mother has used CBZ during pregnancy (23). Decrease of the heart and kidney volume may be related to necrosis of the cells in these two organs as shown in Figures 3 and 4.

On the other hand, the next part of our study showed that IFN- $\gamma$ could protect both organs against adverse effects of CBZ. In earlier research, investigators have confirmed that MIS with IFN- $\gamma$ reduced the prevalence of ethyl carbamate induced cleft palate (24). The mechanisms by which MIS inhibits developmental defects are unidentified; however, there are indications of the maternal cytokines normalizing cell proliferation and apoptosis in the fetus $(8,25)$. Another potential mechanism by which MIS worked was improvement of the placental function (25). Numerous clinical reports have recognized the effects of AEDs on the immune system. AEDs can affect both cellular and humoral immunity, changing the synthesis and the expression of some molecules such as cytokines (13). Wei et al (2010) showed that diazepam prevents human T-cell function by decreasing IFN- $\gamma$ production. It is obvious that IFN- $\gamma$ has immunomodulatory and antiviral activities. IFN- $\gamma$ knockout mice indicated deficits in natural resistance to parasitic, bacterial, and viral infections. In addition to frequent infection, infants with poor production of IFN- $\gamma$ displayed decreased NK cell activity and neutrophil mobility (26). Consistent with these prior researches, we also observed that MIS with IFN- $\gamma$ protects the fetus from adverse effects of $\mathrm{CBZ}$ on the body weight, CRL and histopathological changes in fetal cardiac and renal tissues.

\section{Conclusion}

The current findings revealed that IFN- $\gamma$ could protect against the adverse effects of $\mathrm{CBZ}$ on histopathological changes of the fetal tissues.

\section{References}

1. Borthen I. Obstetrical complications in women with epilepsy. Seizure 2015; $28: 32-34$.

2. Meador KJ, Baker GA, Finnell RH, Kalayjian LA, Liporace JD, Loring DW et al. In utero antiepileptic drug exposure.Neurology 2006; 67 (3): 407-412.

3. Mostacci B, Bisulli F, Poluzzi E, Cocchi G, Piccinni C, Curti A et al. Emilia-Romagna Study on Pregnancy and Exposure to Antiepileptic drugs (ESPEA): a population-based study on prescription patterns, pregnancy outcomes and fetal health. J Neurol Neurosurg Psychiatry 2018; 1-6.

4. Richards N, Reith D, Stitely M, Smith A. Antiepileptic drug exposure in pregnancy and pregnancy outcome from national drug usage data. BMC Pregnancy Childbirth 2018; 18 (1): 84.

5. Jose M, Sreelatha HV, James MV, Arumughan S, Thomas SV. Teratogenic effects of carbamazepine in mice. Annals of Indian Academy of Neurology 2017; 20 (2): 132.

6. Takayasu T, Ishida Y, Kimura A, Nosaka M, Kuninaka Y, Kawaguchi M et al. Distribution of carbamazepine and its metabolites carbamazepine-10, 11-epoxide and iminostilbene in body fluids and organ tissues in five autopsy cases. Forensic Toxicology 2010; 28 (2): 124-128.

7. Hrubec TC, Prater MR, Toops KA, Holladay SD. Reduction in diabetes induced craniofacial defects by maternal immune stimulation. Birth Defects Research Part B: Developmental and Reproductive Toxicology 2006; 77 (1): 1-9.

8. Hrubec TC, Yan M, Ye K, Salafia CM, Holladay SD. Valproic Acid Induced Fetal Malformations Are Reduced by Maternal Immune Stimulation with Granulocyte-Macrophage Colony-Stimulating Factor or Interferon $\gamma$. Anat Rec A Discov Mol Cell Evol Biol 2006; 288 (12): 1303-1309.

9. Punareewattana K, Sharova L, Li W, Ward D, Holladay S. Reduced birth defects caused by maternal immune stimulation may involve increased expression of growth promoting genes and cytokine GM-CSF in the spleen of diabetic ICR mice. International Immunopharmacol 2003; 3 (12): 1639-1655.

10. Punareewattana K, Holladay SD. Immunostimulation by complete Freund's adjuvant, granulocyte macrophage colony stimulating factor, or interferon- $\gamma$ reduces severity of diabetic embryopathy in ICR mice. Birth Defects Research Part A: Clin Mol Teratol 2004; 70 (1): 20-27.

11. Prater MR, Zimmerman KL, Ward DL, Holladay SD. Reduced birth defects caused by maternal immune stimulation in methylnitrosoureaexposed mice: Association with placental improvement. Birth Defects Research Part A: Clin Mol Teratol 2004; 70 (11): 862-869.

12. Sharova L, Gogal Jr R, Sharov A, Chrisman M, Holladay S. Immune stimulation in urethane-exposed pregnant mice increases expression level of spleen leukocyte genes for TGF 33 GM-CSF and other cytokines that may play a role in reduced chemical-induced birth defects. International Immunopharmacol 2002; 2 (10): 1477-1489.

13. Beghi E, Shorvon S. Antiepileptic drugs and the immune system. Epilepsia 2011; 52 (3): 40-44. 
613-618

14. Laudermilch CL, Holladay SD, Sponenberg DP, Saunders GK, Ward DL, Prater MR. Placental improvement and reduced distal limb defects by maternal interferon- $\gamma$ injection in methylnitrosourea exposed mice. Birth Defects Research Part A: Clin Mol Teratol 2005; 73 (9): 597-604.

15. Afshar MS, Moallem A, Baharara J, Takjo T, Golalipour MJ. Preventive effect of vitamin B6 on developmental toxicity of carbamazepine in mice. Iran J Basic Med Sci 2011; 14 (2): 99-106.

16. Namavar MR, Raminfard S, Jahromi ZV, Azari H. Effects of highfat diet on the numerical density and number of neuronal cells and the volume of the mouse hypothalamus: a stereological study. Anat Cell Biol 2012; 45 (3): 178-184.

17. Aneja R, Hake PW, Burroughs TJ, Denenberg AG, Wong HR, Zingarelli B. Epigallocatechin, a green tea polyphenol, attenuates myocardial ischemia reperfusioninjury in rats. Mol Med 2004; 10 (1-6): 55-62.

18. Li W, Qu XN, Han Y, Zheng SW, Wang J, Wang YP. Ameliorative effects of 5-hydroxymethyl-2-furfural (5-HMF), from Schisandra chinensison alcoholic liver oxidative injury in mice. Int J Mol Sci 2015; 16 (2): 2446-2457.

19. Elshama SS, Osman H, Eldin H, El-Kenawy AEM. Teratogenic effect of Carbamazepine use during pregnancy in the mice. Pakistan $\mathbf{J}$ Pharmaceut Scis 2015; 28 (1).

20. Artama M, Auvinen A, Raudaskoski T, Isojärvi I, Isojärvi J. Antiepileptic drug use of women with epilepsy and congenital malformations in offspring. Neurology 2005; 64 (11): 1874-1878.
21. Elshama SS, Osman HEH, El-Kenawy AEM. Histopathological study of developmental toxicity of Carbamazepine in the mice. Intern. Res. J. Appl Basic Sci 2013; 7 (10): 616-622.

22. Okada A, Yabuki A, Matsumoto M, Suzuki S. Development of gender differences in DBA/2 Cr mouse kidney morphology during maturation. J Veter Med Sci 2005; 67 (9): 877-882.

23. Johnson EL, Stowe ZN, Ritchie JC, Newport DJ, Newman ML, B. Knight et al. Carbamazepine clearance and seizure stability during pregnancy. Epilepsy Behavior 2014; 33: 49-53.

24. Sharova L, Sharov A, Sura P, Gogal Jr R, Smith B, Holladay S. Maternal immune stimulation reduces both placental morphologic damage and down-regulated placental growth-factor and cell cycle gene expression caused by urethane: are these events related to reduced teratogenesis? International Immunopharmacol 2003; 3 (7): 945-955.

25. Hrubec T, Punareewattana K, Prater M, Holladay S. Reduction of teratogen induced birth defects in mice: role of maternal immune stimulation. Curr Topics Toxicol 2005; 2006a.

26. Wei M, Li L, Meng R, Fan Y, Liu Y, Tao L, Liu X, Wu C. Suppressive effect of diazepam on IFN-c production by human T cells. Int Immunopharmacol 2010; 10 (3): 267-271.

Received May 30, 2018. Accepted July 3, 2018. 